\title{
ChemComm
}

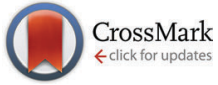

Cite this: Chem. Commun., 2016, 52,13511

Received 22nd July 2016, Accepted 20th October 2016

DOI: $10.1039 / c 6 c c 06057 a$

www.rsc.org/chemcomm

\section{Control of bacterial nitrate assimilation by stabilization of G-quadruplex DNA $\dagger$}

\author{
Zoë A. E. Waller, ${ }^{\text {a }}$ Benjamin J. Pinchbeck, ${ }^{\text {b }}$ Bhovina Seewoodharry Buguth, ${ }^{a}$ \\ Timothy G. Meadows, ${ }^{a}$ David J. Richardson ${ }^{\mathrm{b}}$ and Andrew J. Gates ${ }^{\star b}$
}

\begin{abstract}
Here we present a chemical-biology study in the model soil bacterium Paracoccus denitrificans, where we show ligand-specific control of nitrate assimilation. Stabilization of a G-quadruplex in the promoter region of the nas genes, encoding the assimilatory nitrate/nitrite reductase system, is achieved using known quadruplex ligands and results in attenuation of gene transcription.
\end{abstract}

G-quadruplexes are nucleic acid secondary structures formed from guanine-rich sequences, and comprise a planar arrangement of four guanines that are stabilized by Hoogsteen hydrogen bonding and cations. ${ }^{1}$ These structures have been widely implicated in the control of gene expression for a number of eukaryotic systems. Stabilization of G-quadruplex has been shown to modulate the level of gene expression at both the transcriptional ${ }^{2}$ and translational ${ }^{3}$ level and can lead to cell senescence and apoptosis via disruption of the shelterin complex and inhibition of telomerase in cancer cells. ${ }^{4}$ Despite a number of G-quadruplex sequences being predicted in the genomes of a range of bacteria, ${ }^{5-9}$ so far limited progress has been made in evaluating the breadth of G-quadruplex function in gene regulation and metabolism.

The Gram-negative soil bacterium Paracoccus denitrificans PD1222 exhibits a high degree of metabolic flexibility and may use a range of inorganic nitrogen $(\mathrm{N})$ sources, including nitrate $\left(\mathrm{NO}_{3}{ }^{-}\right)$, nitrite $\left(\mathrm{NO}_{2}{ }^{-}\right)$and ammonium $\left(\mathrm{NH}_{4}{ }^{+}\right)$to support anabolic cellular processes. For growth with $\mathrm{NO}_{3}{ }^{-}$and/or $\mathrm{NO}_{2}{ }^{-}$, expression of regulatory (nasTS) and structural genes (nasABGHC) for the assimilatory $\mathrm{NO}_{3}{ }^{-}$-reductase (Nas) system are required. ${ }^{10}$ Here, nasT plays a pivotal role in encoding the activator component of the $\mathrm{NO}_{3}{ }^{-}$-responsive regulatory complex NasS-NasT, without which the bacterium is unable to grow with $\mathrm{NO}_{3}{ }^{-}$, but retains the capacity to grow with $\mathrm{NH}_{4}{ }^{+}$, as a sole $\mathrm{N}$-source. ${ }^{10,11}$ Given that P. denitrificans has high genomic $\mathrm{G}+\mathrm{C}$ content, approx. $67 \%,{ }^{12}$

\footnotetext{
${ }^{a}$ School of Pharmacy, University of East Anglia, Norwich Research Park, NR4 7TJ, UK. E-mail: z.waller@uea.ac.uk

${ }^{b}$ School of Biological Sciences, University of East Anglia, Norwich Research Park, NR4 7TJ, UK. E-mail: a.gates@uea.ac.uk

$\dagger$ Electronic supplementary information (ESI) available. See DOI: 10.1039/c6cc06057a
}

we decided to investigate whether G-quadruplex structures influenced bacterial growth on inorganic N-sources.

A genome-wide analysis of $P$. denitrificans PD1222, using the Quadparser programme, ${ }^{13}$ revealed the $1.4 \mathrm{Mb}$ genome was predicted to contain 494 putative G-quadruplex forming sequences. One 21 nucleotide sequence tract, 5'-GGGAGCGGGACGGGGGCCGGG-3', predicted to form a canonical G-quadruplex, lies in the intergenic region $150 \mathrm{nt}$ upstream of nasT. Therefore, G-quadruplex formation in DNA at this site may influence expression of the NasT protein, the essential positive regulator for $\mathrm{NO}_{3}{ }^{-}$-dependent growth. ${ }^{11}$

Firstly, to test whether the putative sequence identified adopted G-quadruplex structure in vitro, a combination of ultraviolet (UV) melting, UV difference and circular dichroism (CD) spectroscopies were used to probe the conformation and stability of the DNA. All experiments were performed using the single-stranded 5'-d(GGGAGCGGGACGGGGGCCGGG)-3' oligonucleotide (termed nas $T^{\prime}$ ) in $10 \mathrm{mM}$ sodium cacodylate buffer (pH 7.4), supplemented with $100 \mathrm{mM}$ of additional stabilizing cations $(\mathrm{KCl}, \mathrm{NaCl}, \mathrm{LiCl}$ or $\mathrm{NH}_{4} \mathrm{Cl}$ ). Given that DNA structures absorb UV light differently when folded or unfolded, difference spectra can be used to readily identify various DNA secondary structures formed in solution. Importantly, the presence of intramolecular G-quadruplex structures in a sample can also be inferred by the shape of UV thermal difference spectra (TDS). ${ }^{14} \mathrm{UV}$ spectra of $n a T^{\prime}$ were measured at $20{ }^{\circ} \mathrm{C}$ and $80{ }^{\circ} \mathrm{C}$ with selected cations present to reveal the TDS in different cationic environments. In the presence of $\mathrm{KCl}$, the difference spectrum exhibited positive maxima at 244 and $273 \mathrm{~nm}$, a shoulder at $255 \mathrm{~nm}$, and a negative minimum at $295 \mathrm{~nm}$ (Fig. 1A), comparable to other well-characterized G-quadruplexes. The TDS in the presence of $\mathrm{Na}^{+}$also showed similar features but those in $\mathrm{Li}^{+}$were less well defined and in the presence of $\mathrm{NH}_{4}{ }^{+}$these features were minimal, indicating low populations of folded G-quadruplex in solution. Thermal denaturation experiments monitored at $295 \mathrm{~nm}$ displayed superimposable melting and cooling profiles (Fig. S1, ESI $\dagger$ ), consistent with fast and reversible formation of intramolecular G-quadruplex species. Notably, melting transitions were independent of oligonucleotide concentration, also consistent with intramolecular G-quadruplex formation. 

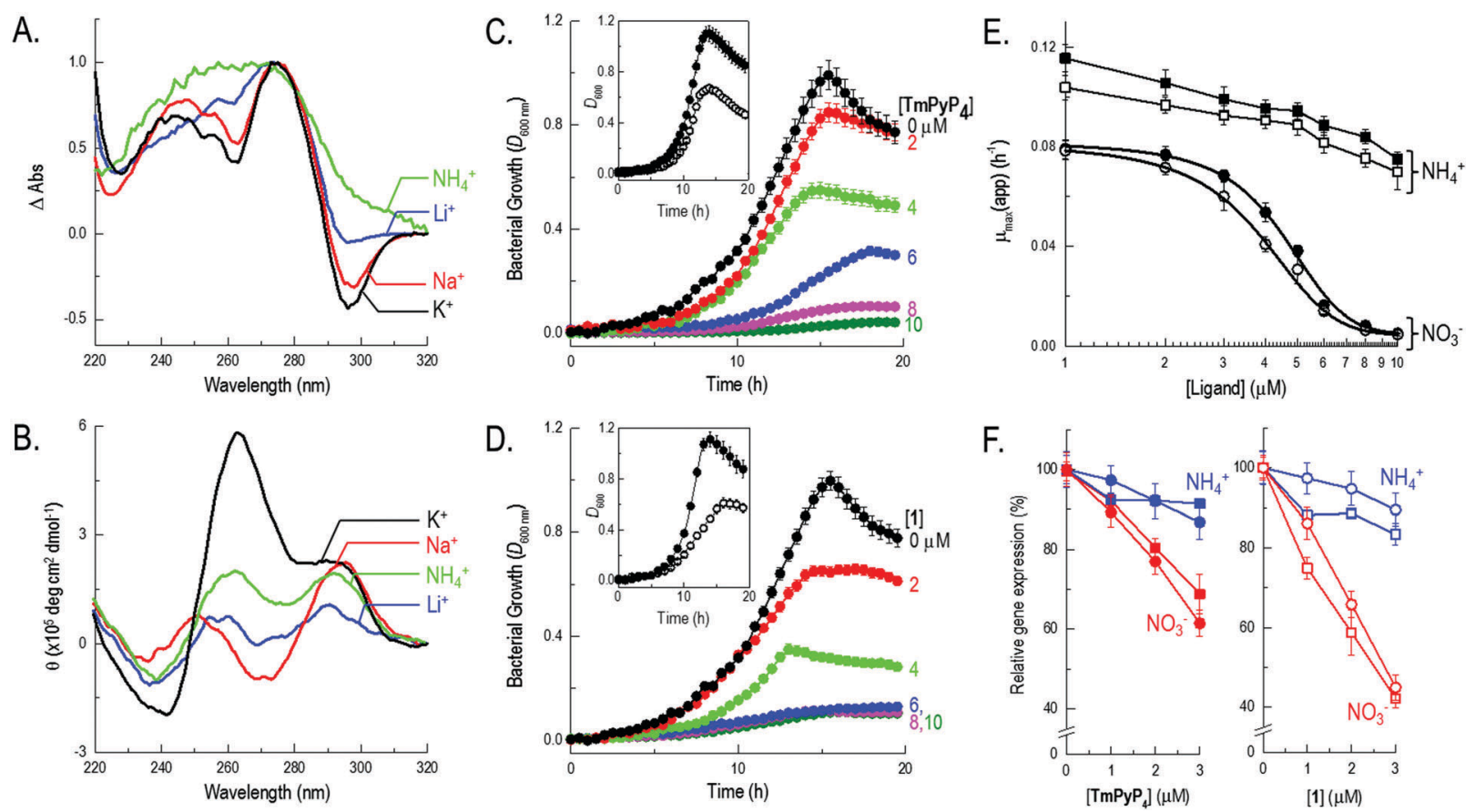

Fig. 1 Biophysical characterization of nas $T^{\prime}$ and impact of quadruplex-binding ligands on bacterial growth and gene expression. (A) Thermal difference and (B) circular dichroism spectra in $10 \mathrm{mM}$ sodium cacodylate buffer $(\mathrm{pH} 7.4)$ supplemented with either $100 \mathrm{mM} \mathrm{KCl,} \mathrm{NaCl}, \mathrm{NH}{ }_{4} \mathrm{Cl}$ or LiCl. Growth curves for $P$. denitrificans with 0-10 $\mu \mathrm{M} \mathrm{TmPyP}_{4}$ (C) and 1 (D) during $\mathrm{NO}_{3}{ }^{-}$-dependent growth. Comparative growth curves with 0 (solid symbols) and $10 \mu \mathrm{M}$ (outline symbols) ligand during $\mathrm{NH}_{4}{ }^{+}$-dependent growth are inset within the relevant panel. (E) Concentration dependence for TmPyP $\mathbf{P}_{4}$ (solid symbols) and 1 (outline symbols) on the maximal specific growth rate during $\mathrm{NO}_{3}{ }^{-}$-dependent (circles) and $\mathrm{NH}_{4}{ }^{+}$-dependent (squares) growth. (F) The impact of sub-lethal concentrations $(0-3 \mu \mathrm{M})$ of $\mathrm{TmPyP}_{4}$ (left) and $\mathbf{1}$ (right) on gene expression measured during $\mathrm{NO}_{3}{ }^{-}$-dependent (red) or $\mathrm{NH}_{4}{ }^{+}$-dependent (blue) growth of $P$. denitrificans, using two different methods. Squares represent $\beta$-galactosidase activity from cells harbouring a nas $T$-lac $Z$ transcriptional reporter-fusion plasmid. Circles show qRT-PCR data for nasT expression relative to the polB control.

DNA melting and cooling curves for nas $T^{\prime}$ in buffer containing $100 \mathrm{mM} \mathrm{KCl}$, show a single transition with a $T_{\mathrm{m}}$ of $69^{\circ} \mathrm{C}$ (Fig. S1 and Table S1, ESI $\dagger)$. This structure is less stable in the presence of $\mathrm{Na}^{+}\left(T_{\mathrm{m}}=64{ }^{\circ} \mathrm{C}\right)$ and even less stable in $\mathrm{Li}^{+}$where a full melting transition was not observed under the conditions of the experiment. This data is consistent with the recognized cation preference for G-quadruplex structures (i.e., $\mathrm{K}^{+}>\mathrm{NH}_{4}{ }^{+}>$ $\left.\mathrm{Na}^{+}>\mathrm{Li}^{+}\right) \cdot{ }^{15}$ However, experiments in the presence of $100 \mathrm{mM}$ $\mathrm{NH}_{4}{ }^{+}$also did not show a complete melting/annealing transition, which is notably different to typical G-quadruplex cationic preference and implies relative insensitivity to $\mathrm{NH}_{4}{ }^{+}$compared to other cations investigated. This effect is similar to that observed recently in Treponema pallidum, where a potential quadruplexforming sequence was shown to have remarkable $\mathrm{K}^{+}$selectivity and atypical structural plasticity. ${ }^{16}$ We considered the insensitivity of nasT' to $\mathrm{NH}_{4}{ }^{+}$important, as $\mathrm{NH}_{4}{ }^{+}$-dependent growth of $P$. denitrificans would proceed unaffected by G-quadruplex formation and thus $\mathrm{NH}_{4}{ }^{+}$could be used as a control in growth experiments. CD spectroscopy can provide detailed information regarding the conformation of a G-quadruplex structure and can also be used to follow subsequent changes in population that may occur on ligand binding. Parallel quadruplexes exhibit a strong positive band at $263 \mathrm{~nm}$ and a negative band at $240 \mathrm{~nm}$, while antiparallel structures show a negative band at $260 \mathrm{~nm}$ and a positive band at $295 \mathrm{~nm} .{ }^{17}$ In buffer containing $100 \mathrm{mM} \mathrm{KCl}$, the CD spectrum of nast $T^{\prime}$ shows strong features at 263 and $295 \mathrm{~nm}$, suggesting that a mixture of parallel and antiparallel conformations of G-quadruplex form under these conditions (Fig. 1B). Spectra for $n a s T^{\prime}$ in $100 \mathrm{mM} \mathrm{NaCl}$ are devoid of appreciable positive bands at $263 \mathrm{~nm}$, the intensity of the $295 \mathrm{~nm}$ bands are strong and complemented by peaks at $270 \mathrm{~nm}$. These spectral features indicate antiparallel conformation. However, spectra for $n a s T^{\prime}$ in the presence of $\mathrm{NH}_{4} \mathrm{Cl}$ show peaks of equally low intensity at 263 and $295 \mathrm{~nm}$, perhaps indicative of some residual G-quadruplex formation, but the signals are weak. The low signal intensity observed in the presence of $\mathrm{Li}^{+}$is consistent with the typical cation preference for G-quadruplexes. Collectively, this spectroscopic data suggests the topology of the nas $T^{\prime}$ G-quadruplex in vitro is significantly influenced by the type of cation present in solution and demonstrates particular insensitivity to the presence of $\mathrm{NH}_{4}{ }^{+}$. The formation of antiparallel conformations is unsurprising as there are no single nucleotide loops to favour parallel conformations. It is likely that the first, second and fourth sets of G-tracts are fixed, but there is opportunity for conformational flexibility with the third G-tract, which is composed of five guanines.

To investigate the effect of ligand interactions on the $n a s T^{\prime}$ G-quadruplex we used previously characterized ligands, which have been shown to interact with G-quadruplex structures. $\mathrm{TmPyP}_{\mathbf{4}}$ and $\mathbf{1}$ are structurally distinct, but both have been previously shown to bind G-quadruplex and affect biological systems via mechanisms that involve ligand-quadruplex interactions. 
For example, $\mathbf{T m P y P}_{4}$ is a cationic porphyrin, which has been shown to down-regulate the level of $c-M Y C,{ }^{18} K R A S,{ }^{19}$ and $h T E R T^{20}$ expression and also inhibit telomerase. By contrast, $\mathbf{1}$ is a benzophenoxazine ligand that has previously been shown to decrease the level of gene expression for $c-K I T{ }^{21}$ All biophysical experiments were performed in the presence of $100 \mathrm{mM} \mathrm{NaCl}$, to reflect the concentration of $\mathrm{Na}^{+}$in which these cells are usually grown. Addition of ligand to nasT ${ }^{\prime}$ DNA using CD revealed changes in peak maxima consistent with binding (Fig. S2, ESI $\dagger$ ). Quantitative data was obtained using fluorescence titrations, where binding affinities were determined for $\mathbf{T m P y P}_{\mathbf{4}}$ and $\mathbf{1}$ to the nasT' G-quadruplex (Fig. S3, ESI $\dagger$ ). The first dissociation constant for $\mathbf{T m P y P}_{4}$ was calculated to be $0.13 \pm 0.01 \mu \mathrm{M}$, with a second binding site an order of magnitude weaker $(5.0 \pm 2.0 \mu \mathrm{M})$. Ligand $\mathbf{1}$ showed slightly lower affinity for the nas $T^{\prime}$ G-quadruplex with a dissociation constant of $1.8 \pm 0.01 \mu \mathrm{M}$ for the first binding site, and the second an order of magnitude weaker $(44 \pm 0.01 \mu \mathrm{M})$. These binding affinities are in-line with previous reports of G-quadruplex binding for these ligands. Ligand-quadruplex interactions were also evaluated using Förster resonance energy transfer (FRET) melting, which provides a measure of the ligand-induced stabilization of a folded quadruplex. Ligand 1 was found to show moderate stabilization at $1 \mu \mathrm{M}\left(\Delta T_{\mathrm{m}}=5{ }^{\circ} \mathrm{C}\right.$, Fig. S4, ESI $\left.\dagger\right)$ whereas $\mathbf{T m P y P}_{\mathbf{4}}$ shows significantly higher stabilization $\left(\Delta T_{\mathrm{m}}=30{ }^{\circ} \mathrm{C}\right.$, Fig. S4, ESI $\dagger$ ). This is complementary to the respective dissociation constants. Importantly, the CD, FRET melting and the fluorescence titration experiments indicate that $\mathbf{T m P y P}_{\mathbf{4}}$ and $\mathbf{1}$ readily interact with nasT' G-quadruplex DNA.

Given the interesting conformational and stability profiles observed for the nas $T^{\prime}$ G-quadruplex in in vitro experiments, the effect of $\mathbf{K C l}$ and ligands $\mathbf{T m P y P}_{\mathbf{4}}$ and $\mathbf{1}$ on Nas-dependent and Nas-independent bacterial growth was investigated. $P$. denitrificans can use $\mathrm{NO}_{3}{ }^{-}$for growth, where catalytic reduction of $\mathrm{NO}_{3}{ }^{-}$by Nas generates cytoplasmic $\mathrm{NH}_{4}{ }^{+}$that is used for biosynthesis of cellular components. However, Nas-independent growth is readily achieved by supplementing growth media with $\mathrm{NH}_{4}{ }^{+}$, the product of assimilatory $\mathrm{NO}_{3}{ }^{-} / \mathrm{NO}_{2}{ }^{-}$reduction and a weak ligand to nasT ${ }^{\prime}$, in place of $\mathrm{NO}_{3}{ }^{-}$. From this, growth with $\mathrm{NO}_{3}{ }^{-}$compared to $\mathrm{NH}_{4}{ }^{+}$ (as a control) will indicate the effect of the stabilization of the G-quadruplex in nasT. Growth experiments in the presence of either $10 \mathrm{mM} \mathrm{NO}_{3}{ }^{-}$or $\mathrm{NH}_{4}{ }^{+}$reach a similar cell density, i.e. attenuance $(D)$ measured at $600 \mathrm{~nm}$, following $20 \mathrm{~h}$ incubation at $30{ }^{\circ} \mathrm{C}$ (i.e., compare black solid symbols in Fig. $1 \mathrm{C}$ and D with corresponding insets). Additional control experiments using $\mathrm{N}$-deficient growth media revealed neither $\mathbf{T m P y P}_{\mathbf{4}}$ nor $\mathbf{1}$ could act as an N-source for bacterial growth (Fig. S5, ESI $\dagger$ ). To assess the impact of G-quadruplex ligands on the growth of $P$. denitrificans cells, growth curves were measured for cultures using either $\mathrm{NH}_{4}{ }^{+}$ or $\mathrm{NO}_{3}{ }^{-}$as sole $\mathrm{N}$-source, in the presence of varying concentrations of $\mathbf{T m P y P}_{4}, \mathbf{1}$ or $\mathrm{KCl}$. Addition of either $\mathbf{T m P y P}_{\mathbf{4}}$ or $\mathbf{1}$ in the low-micromolar range revealed a clear deleterious effect on $\mathrm{NO}_{3}{ }^{-}$-dependent bacterial growth (Fig. $1 \mathrm{C}$ and D). However, the presence of either ligand failed to demonstrate similar potency over the same concentration range for cells when grown with $\mathrm{NH}_{4}{ }^{+}$, when the Nas system is not required for growth. Growth with either $\mathrm{N}$-source was unaffected by addition of $\mathrm{KCl}$ up to $50 \mathrm{mM}$, however, above $50 \mathrm{mM} \mathrm{NO}_{3}{ }^{-}$-dependent growth showed sensitivity to $\mathrm{KCl}$ relative to $\mathrm{NH}_{4}{ }^{+}$-dependent growth (Fig. S6, ESI $\dagger$ ). The fact that $\mathrm{KCl}$ sensitivity was observed during growth with $\mathrm{NO}_{3}{ }^{-}$is consistent with $\mathrm{K}^{+}$being a strong ligand for G-quadruplexes. However, in bacteria, there are numerous mechanisms for $\mathrm{K}^{+}$homeostasis, ${ }^{22,23}$ and the requirement of high-millimolar concentrations of $\mathrm{KCl}$ required to attenuate growth may reflect the excess required to overcome these systems and alter the intracellular $\mathrm{K}^{+}$pool.

Further analysis of growth data presented for $\mathbf{T m P y P}_{\mathbf{4}}$ and $\mathbf{1}$ in Fig. 1C and D respectively, in semi-log form, was used to determine values for the apparent maximal specific growth rate $\left[\mu_{\max }(\right.$ app. $\left.), \mathrm{h}^{-1}\right]$, during exponential phase in each experiment. Values obtained for $\mu_{\max }$ (app.) versus ligand concentration are presented in Fig. 1E. Here, it was clear that Nas-dependent growth of $P$. denitrificans with $\mathrm{NO}_{3}{ }^{-}$was profoundly affected by both G-quadruplex ligands $\mathbf{T m P y P}_{\mathbf{4}}$ and $\mathbf{1}$ when compared to Nas-independent growth with $\mathrm{NH}_{4}{ }^{+}$. During growth on $\mathrm{NO}_{3}{ }^{-}$and $\mathrm{NH}_{4}{ }^{+}$values for $\mu_{\text {max }}$ (app.) fell by $\sim 90 \%$ and $\sim 25 \%$, respectively in the presence of $10 \mu \mathrm{M} \mathbf{T m P y P}_{\mathbf{4}}$, and analogous behaviour was observed with 1. Data obtained during $\mathrm{NO}_{3}{ }^{-}$-dependent growth was fitted using a dose response curve. $\mathrm{IC}_{50}$ values of $4.5 \pm 0.2$ and $3.8 \pm 0.3 \mu \mathrm{M}$ were determined for bacterial growth inhibition by $\mathrm{TmPyP}_{4}$ and 1, respectively (Fig. 1E). Notably, these $\mathrm{IC}_{50}$ values were in agreement with the micromolar dissociation constants determined for both quadruplex-ligands in vitro, where slight differences can be attributed to differences in cell uptake. The results suggest that in the presence of quadruplex-ligands, $P$. denitrificans cells experience less efficient growth when $\mathrm{NO}_{3}{ }^{-}$is used rather than $\mathrm{NH}_{4}{ }^{+}$, which can be attributed to inhibition of Nas expression by G-quadruplex stabilization. We therefore suggest that bacterial growth proceeds at greater ligand concentrations when $\mathrm{NH}_{4}{ }^{+}$is used as an $\mathrm{N}$-source because the $\mathrm{NO}_{3}{ }^{-}$assimilation pathway is not required for cellular growth. Nevertheless, the impact of both exogenous ligands $\mathbf{T m P y P}_{\mathbf{4}}$ and $\mathbf{1}$ on bacterial metabolism more generally can be gauged from the $\mathrm{NH}_{4}{ }^{+}$-dependent growth profiles observed, which show a modest background decrease in growth with increasing ligand concentration. Here, stabilization of different G-quadruplex forming sequences present elsewhere on the genome (at loci unconnected with expression and/or functional maturation of Nas), and/or within RNA pools, may be responsible for this background decrease in growth.

In order to test whether expression of the nas gene cluster was modulated by the nasT' $T^{\prime}$ DNA G-quadruplex, a plasmid-borne transcriptional nasT-lacZ gene-reporter fusion construct was produced that contained a $200 \mathrm{nt}$ region upstream of the nasT gene, including the promoter-proximal DNA G-quadruplex forming sequence nas $T^{\prime}$. Expression of this nasT-lacZ gene-reporter construct was measured using $P$. denitrificans cells that were grown in the presence of $\mathbf{T m P y P}_{\mathbf{4}}$ or $\mathbf{1}$. In $P$. denitrificans, expression of nasTS is up-regulated when intracellular $\mathrm{NH}_{4}{ }^{+}$is limited. ${ }^{10,11}$ In the absence of quadruplex ligands, expression of nasT-lacZ and thus $\beta$-galactosidase activity is an order of magnitude higher with $\mathrm{NO}_{3}{ }^{-}(3790 \pm 120$ Miller units $)$, compared to $\mathrm{NH}_{4}{ }^{+}$ $(290 \pm 20$ Miller units), as sole N-source (Fig. S7, ESI $\dagger$ ). When $\beta$-galactosidase activity was normalized relative to zero ligand concentration, it is apparent that sub-lethal concentrations 
(i.e., $0-3 \mu \mathrm{M}$ ) of $\mathbf{T m P y P}_{4}$ or $\mathbf{1}$ have a clear inhibitory effect on nasT expression in $P$. denitrificans cells obtained from $\mathrm{NO}_{3}{ }^{-}$dependent, but not $\mathrm{NH}_{4}{ }^{+}$-dependent, cultures (Fig. 1F). Given the regulatory target for NasT is the $5^{\prime}$ untranslated region of the nas $A$ mRNA that encodes the structural genes for Nas, ${ }^{10,11}$ as expected, further experiments using a nasA-lacZ reporter-fusion revealed that expression of the structural nas genes follow a similar liganddependent profile observed for the nasT-lacZ reporter (Fig. S7, ESI $\dagger$ ). However, it is important to note that the response of the nasA-lacZ reporter to quadruplex-ligands is indirect and a consequence of low nasT expression. Further quantitative real timePCR (qRT-PCR) experiments showed that the same trend is observed in vivo (Fig. 1F). Collectively, these findings demonstrate that, with $\mathrm{NO}_{3}{ }^{-}$as sole $\mathrm{N}$-source the bacterium is unable to grow due to the ligand-induced stabilization of the nas $T^{\prime}$ G-quadruplex secondary structure in the nasT promoter.

The ability of heterotrophic bacteria to use $\mathrm{NO}_{3}{ }^{-}$for growth is a widespread trait and a key process of the biogeochemical $\mathrm{N}$-cycle. ${ }^{10}$ Herein we describe specific control of $\mathrm{NO}_{3}{ }^{-}$-dependent growth in $P$. denitrificans by stabilization of a G-quadruplex forming sequence nas $T^{\prime}$. This sequence is present upstream of the nasTS genes that are essential for expression of Nas, and for bacterial growth with $\mathrm{NO}_{3}{ }^{-}$, but not $\mathrm{NH}_{4}{ }^{+}$(Fig. 2). Biophysical experiments confirm the DNA sequence identified readily adopts a G-quadruplex secondary structure in vitro; and that the structure is able to bind published quadruplex ligands, including $\mathbf{T m P y} \mathbf{P}_{\mathbf{4}}$ and 1. In addition, the cations $\mathrm{K}^{+}$and $\mathrm{Na}^{+}$were also shown to stabilize quadruplex structure. Unlike other DNA quadruplexforming sequences, nasT' was unexpectedly insensitive to $\mathrm{NH}_{4}{ }^{+}$. A series of complementary in vivo studies were also performed to test the role of nas $T^{\prime}$ during Nas-dependent bacterial growth. Here, bacterial growth on $\mathrm{NO}_{3}{ }^{-}$was found to be sensitive to $\mathrm{KCl}$, TmPyP $_{4}$ and 1, which bind nasT' $T^{\prime}$ NA in vitro. However, $\mathrm{NH}_{4}{ }^{+}$ dependent bacterial growth (i.e., Nas-independent metabolism), was comparatively unaffected by these ligands. Transcriptional gene-reporter fusion experiments revealed that expression of genes encoding Nas were attenuated in the presence of quadruplex

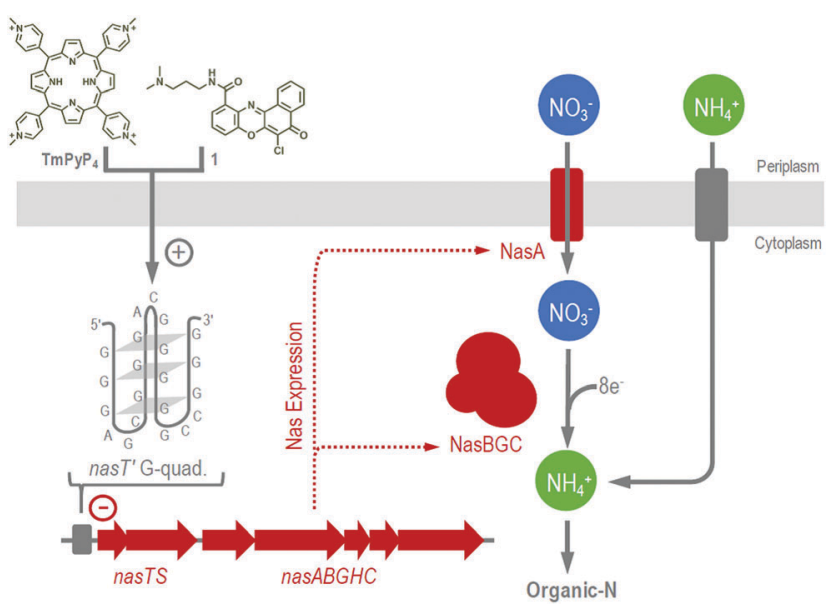

Fig. 2 Proposed mechanism for quadruplex-ligand control of Nas-dependent growth of $P$. denitrificans. The + and - symbols represent stabilization of the nas $T^{\prime}$ G-quadruplex and inhibition of nas transcription, respectively. ligands during $\mathrm{NO}_{3}{ }^{-}$-dependent, but not $\mathrm{NH}_{4}{ }^{+}$-dependent growth. Finally, results from qRT-PCR experiments are consistent with the proposed model where ligand-quadruplex interactions can decrease transcription of the nas genes in vivo. To our knowledge, this study represents the first time that control of bacterial $\mathrm{N}$-metabolism by G-quadruplex structure has been explored. In the case of bacterial $\mathrm{NO}_{3}{ }^{-}$-utilization, there appears to be a very fine balance between quadruplex stability, nasT function and bacterial growth. These results suggest that exogenous quadruplex-binding ligands readily enter bacterial cells and have specific targets. Therefore, such chemical ligands may be applied to cells to selectively control metabolic pathways. In future, quadruplex-ligands may be applied to control microbial utilization of anthropogenic-N and may have the potential to direct $\mathrm{N}$-flux in the environment.

This work was funded by the Biotechnology and Biological Sciences Research Council [grant ref. BB/M00256X/1 (to A. J. G.) and BB/L02229X/1 (to Z. A. E. W.)] and the Royal Society [grant ref. RG140746 (to A. J. G. and Z. A. E. W.)]. D. J. R. is a Royal Society Wolfson Foundation Merit Award holder. We also thank Dr Myles Cheesman and the Henry Wellcome Laboratories for Biological Chemistry at UEA for the use of the CD facilities.

\section{Notes and references}

1 S. Balasubramanian, L. H. Hurley and S. Neidle, Nat. Rev. Drug Discovery, 2011, 10, 261.

2 R. Rodriguez, K. M. Miller, J. V. Forment, C. R. Bradshaw, M. Nikan, S. Britton, T. Oelschlaegel, B. Xhemalce, S. Balasubramanian and S. P. Jackson, Nat. Chem. Biol., 2012, 8, 301.

3 A. L. Wolfe, K. Singh, Y. Zhong, P. Drewe, V. K. Rajasekhar, V. R. Sanghvi, K. J. Mavrakis, M. Jiang, J. E. Roderick, J. Van der Meulen, J. H. Schatz, C. M. Rodrigo, C. Zhao, P. Rondou, E. de Stanchina, J. Teruya-Feldstein, M. A. Kelliher, F. Speleman, J. A. Porco Jr., J. Pelletier, G. Ratsch and H. G. Wendel, Nature, 2014, 513, 65.

4 B. Maji, K. Kumar, M. Kaulage, K. Muniyappa and S. Bhattacharya, J. Med. Chem., 2014, 57, 6973.

5 N. Beaume, R. Pathak, V. K. Yadav, S. Kota, H. S. Misra, H. K. Gautam and S. Chowdhury, Nucleic Acids Res., 2013, 41, 76.

6 M. Wieland and J. S. Hartig, Chem. Biol., 2007, 14, 757.

7 C. Rehm, L. A. Wurmthaler, Y. Li, T. Frickey and J. S. Hartig, PLoS One, 2015, 10, e0144275.

8 L. A. Cahoon and H. S. Seifert, Science, 2009, 325, 764.

9 L. A. Cahoon and H. S. Seifert, PLoS Pathog., 2013, 9, e1003074.

10 A. J. Gates, V. M. Luque-Almagro, A. D. Goddard, S. J. Ferguson, M. D. Roldan and D. J. Richardson, Biochem. J., 2011, 435, 743.

11 V. M. Luque-Almagro, V. J. Lyall, S. J. Ferguson, M. D. Roldan, D. J. Richardson and A. J. Gates, J. Biol. Chem., 2013, 288, 29692.

12 S. C. Baker, S. J. Ferguson, B. Ludwig, M. D. Page, O. M. Richter and R. J. van Spanning, Microbiol. Mol. Biol. Rev., 1998, 62, 1046.

13 J. L. Huppert and S. Balasubramanian, Nucleic Acids Res., 2005, 33, 2908.

14 J. L. Mergny, J. Li, L. Lacroix, S. Amrane and J. B. Chaires, Nucleic Acids Res., 2005, 33, e138.

15 A. Wong and G. Wu, J. Am. Chem. Soc., 2003, 125, 13895.

16 C. Rehm, I. T. Holder, A. Gross, F. Wojciechowski, M. Urban, M. Sinn, M. Drescher and J. S. Hartig, Chem. Sci., 2014, 5, 2809.

17 J. Kypr, I. Kejnovska, D. Renciuk and M. Vorlickova, Nucleic Acids Res., 2009, 37, 1713.

18 A. Siddiqui-Jain, C. L. Grand, D. J. Bearss and L. H. Hurley, Proc. Natl. Acad. Sci. U. S. A., 2002, 99, 11593.

19 S. Cogoi and L. E. Xodo, Nucleic Acids Res., 2006, 34, 2536.

20 C. L. Grand, H. Y. Han, R. M. Munoz, S. Weitman, D. D. Von Hoff, L. H. Hurley and D. J. Bearss, Mol. Cancer Ther., 2002, 1, 565.

21 K. I. E. McLuckie, Z. A. E. Waller, D. A. Sanders, D. Alves, R. Rodriguez, J. Dash, G. J. McKenzie, A. R. Venkitaraman and S. Balasubramanian, J. Am. Chem. Soc., 2011, 133, 2658.

22 W. Epstein, Prog. Nucleic Acid Res. Mol. Biol., 2003, 75, 293.

23 I. Kucera, Biochim. Biophys. Acta, 2005, 1709, 113. 